\title{
Does collimation affect patient dose in antero-posterior thoraco-lumbar spine?
}

\section{ABSTRACT}

BACKGROUND: The purpose of this study is to determine the effect of collimation on the lifetime attributable risk (LAR) of cancer incidence in all body organs (effective risk) in patients undergoing antero-posterior (AP) examinations of the spine. This is of particular importance for patients suffering from scoliosis as in their case regular repeat examinations are required and also because such patients are usually young and more susceptible to the effects of ionising radiation than are older patients.

METHOD: High sensitivity thermo-luminescent dosimeters (TLDs) were used to measure radiation dose to all organs of an adult male dosimetry phantom, positioned for an AP projection of the thoraco-lumbar spine.

Exposures were made, first applying tight collimation and then subsequently with loose collimation, using the same acquisition factors. In each case, the individual TLDs were measured to determine the local absorbed dose and those representing each organ averaged to calculate organ dose.

This information was then used to calculate the effective risk of cancer incidence for each decade of life from 20 to 80 , and to compare the likelihood of cancer incidence when using tight and loose collimation.

RESULTS: The calculated figures for effective risk of cancer incidence suggest that the risk when using loose collimation compared to the use of tight collimation is over three times as high and this is the case across all age decades from 20 to 80 .

CONCLUSION: Tight collimation can greatly reduce radiation dose and risk of cancer incidence. However collimation in scoliotic patients can be necessarily limited.

Keywords: Collimation, radiation dose, lifetime attributable risk, cancer incidence, thoraco-lumbar spine, scoliosis.

\section{INTRODUCTION}

The reduction of ionising radiation dose in radiography, whilst at the same time achieving images of optimum quality, is of paramount importance. One of the most important factors to attain this is by appropriate collimation of the primary X-ray beam. Aside from the potential for dose reduction, accurate and tight collimation can result in an improvement of image quality by reduction of scatter ${ }^{1}$.

Surprisingly little empirical research has been reported in the literature with regard to collimation and dose reduction. Powys et $\mathrm{al}^{2}$, for example, performed three levels of collimation of a lateral projection of the facial bones and determined the comparative doses to the thyroid and the lens of the eye, using a head and thorax phantom and an Unfors dose meter. They found an appreciable reduction in dose to the thyroid with tighter collimation, although less so to the lenses of the eyes. Lee et $\mathrm{al}^{3}$ examined the effects of 'stepwise collimation' in scoliosis but employed only mathematically simulated dose estimations using tissue-weighting factors and a Monte Carlo method. They found that there were large decreases in effective dose generally, but less so to organs in the target site of the examination. They also pointed out that, depending upon the extent of the scoliosis, accurate collimation can be difficult due to the nature of the condition.

Limitations of the use of a single dose meter $^{2}$ and no direct dose measurements ${ }^{3}$, suggest that improvements can be made to the experimental design of previous research to investigate how dose varies between tight and loose collimation. This should lead to more accurate data on which to develop arguments. Our work builds directly on this previous research through the use of TLDs in a human dosimetry phantom in order to make more accurate estimations of organ dose. Using organ dose, effective dose and effective risk of radiation-induced cancer was then calculated. 
For the purposes of our investigation, the thoraco-lumbar spine was chosen and antero-posterior (AP) projections performed on a phantom. One reason for this is that to determine the extent and progression of scoliosis, X-ray examinations of this area are repeated on a regular basis during the earlier years of life when the body is more susceptible to the adverse effects of ionising radiation ${ }^{4}$. This will have an obvious impact on the effective risk of cancer incidence for such patients. Another reason for this choice of area is that, as mentioned by Zetterberg et $\mathrm{al}^{5}$, one of the highest effective radiation doses in general radiography is found in lumbar spine examinations.

The purpose of our work is to determine whether differences to organ dose, effective dose and effective risk for a range of ages exist when using tight collimation compared to loose collimation, as defined in the Data Acquisition section below. The effects on male patients only are considered as the phantom used was male in structure.

\section{METHOD}

Our method uses an adult male dosimetry phantom with installed thermo-luminescent dosimeters (TLDs). This was exposed under tight and loose collimation for AP spine (see Figures 1 and 2). Using the TLD data, organ dose and effective dose were calculated along with effective risk for a range of ages.

\section{Dosimetry measurements}

A CIRS (Computerized Imaging Reference Systems Inc.) Atom model 701-D adult male dosimetry phantom was used for direct dose measurements and included 271 locations for TLD placement (CIRS, Norfolk Virginia). Annealed TLDs (TLD100H [LiF: Mg, Cu, P] (Thermo Fisher Scientific, Waltham, Massachusetts) were placed in each location for the exposures. The charges on the exposed TLDs were read using a Harshaw 3500 TLD reader (Thermo Fisher Scientific, Waltham, Massachusetts). Prior to use, the TLDs were grouped into batches of similar response. Calibration exposures at $75 \mathrm{kVp}$ and various $\mathrm{mAs}$ values were then applied directly to the TLDs with a source distance of $100 \mathrm{~cm}$. These were completed for randomly-selected TLDs from each group along with an Unfors Mult-O-Meter 401 (Billdal, Sweden) in order to produce calibration factors for each group, as seen in Table 1. These calibration factors, along with readings of background radiation, were applied to the raw exposure figures obtained from the phantom TLDs (see Table 2). Great care was taken to position each specific TLD in exactly the same location within the phantom for both tight and loose collimation exposures in order to account for any variation in response between different individual TLDs.

\section{Imaging equipment}

X-ray exposures were made using a Wolverson Arcoma Arco general radiography system (Arcoma, Annavägen, Sweden) with a Varian 130 HS X-ray tube and high-frequency generator. Total filtration was $3 \mathrm{~mm}$ Al (inherent $0.5 \mathrm{~mm}$, added $2.5 \mathrm{~mm} \mathrm{Al}$ ). Quality control of the X-ray system was performed, including tube output; kV accuracy; AEC consistency and repeatability; and light beam alignment, centring and collimation, and the results fell within local and manufacturer's tolerances in compliance with the Institute of Physics and Engineering in Medicine (IPEM) Report 32.

\section{Data acquisition}

Two sets of AP projection exposures were made of the phantom. In each case, ten exposures at one minute intervals were made and then the dose readings averaged in order to account for any random error in output of the X-ray system ${ }^{6,7}$. The first acquisition, using tight collimation, was set to the width of the thoraco-lumbar spine to include the pedicles laterally, the sacro-iliac joints inferiorly and as much as possible superiorly using a $35 \times 43 \mathrm{~cm}$ sensor, the physical measurement of the collimated field at the front surface of the phantom being $10 \mathrm{~cm}$ wide and $46 \mathrm{~cm}$ tall (see Figure 1). For the second acquisition (loose collimation), the lateral collimation was opened to include the full width of the trunk, $38 \mathrm{~cm}$ wide (see Figure 2). We acknowledge that backscatter would increase with loose collimation but we have not attempted to quantify this. These two scenarios accommodate the two extremes of lateral collimation for AP spine when imaging scoliosis. 
Exposure factors for the phantom were $75 \mathrm{kVp}$ and $16 \mathrm{mAs}$ at a SID (Source to Image receptor Distance) of $180 \mathrm{~cm}$. The choice of $\mathrm{kVp}$ was based on the work of Al Qaroot et $\mathrm{al}^{8}$. Initial test exposures were performed using the Automatic Exposure Control (AEC) to determine the optimum mAs value, and this was set manually for all subsequent tight and loose collimation exposures with the aim of delivering a consistent tube output.

\section{Analysis}

For each TLD, the average group background radiation was subtracted from the raw exposure reading and the resulting figure divided by ten to account for the ten exposures made. That figure was then multiplied by the TLD group calibration factor in order to account for variations in TLD sensitivity and to ensure that resultant dose figures in $\mathrm{mGy}$ relate to the nanocoulomb $(\mathrm{nC})$ readings on the TLDs (see Table 2 ).

The average dose for all of the TLDs representing each organ were calculated. These figures were then multiplied by the estimates given in Table 12D-1 Lifetime Attributable Risk of Cancer Incidence of BEIR VII Phase $^{4}$ for each decade of life, the figures used being for male patients only as a male dosimetry phantom was used. As the BEIR VII figures represent the Lifetime Attributable Risk (LAR) of cancer incidence in number of cases per 100,000 persons exposed to a single dose of $0.1 \mathrm{~Gy}$, they have been adjusted to represent the number of cases per 1,000,000 persons exposed to the given doses in $\mathrm{mGy}$.

Effective dose was calculated using the following equation:

$$
E=\sum_{\mathrm{T}} W_{\mathrm{T}} \sum_{\mathrm{R}} W_{\mathrm{R}} D_{\mathrm{T}, \mathrm{R}}
$$

Where $W_{R} D_{T, R}$ is the equivalent dose in a tissue or organ, $T$, and $W_{T}$ is the tissue weighting factor and the tissue-weighting factors stated in ICRP report $103^{9}$. The Radiation Weighting Factor for photons (eg, $\mathrm{X}$-rays) is 1.

\section{RESULTS}

Table 3 compares the LAR of radiation-induced cancer in different body organs and the effective risk (the total) in number of cases per 1,000,000 persons exposed for each decade of life when using tight collimation and loose collimation. Figure $\mathbf{3}$ presents the same information graphically. Table $\mathbf{4}$ shows the increase in average organ dose in $\mathrm{mGy}$ for each of the listed organs when using loose collimation compared to tight collimation, and includes the percentage change to organ dose for each organ when collimation of the X-ray beam is opened from tightly-collimated to a much wider field as may be necessary in cases of severe scoliosis. The effective organ dose in mSv for each organ (after adjustment for tissue-weighting) using tight and loose collimation is given in Table $\mathbf{5}$ for comparison. Effective dose figures are calculated by totalling the tissueweighted doses of all organs.

The calculated figures for LAR of cancer incidence as a result of a single exposure of X-rays using the data acquisition factors given earlier, across age decades from 20 s to 80 s, are indicated in Table 3 . The figures for each individual organ are combined to produce effective risk for each age decade, and the figures for tight collimation and loose collimation are presented adjacent to each other for ease of comparison. In each case, the figures suggest that the risk when using loose collimation is over three times as high as when using tight collimation ( $p=0.001)$. Specifically, the numbers show an increase of effective risk by a factor of 3.22 at age $20,3.24$ at age $30,3.27$ at age 40, 3.30 at age 50, 3.36 at age $60,3.43$ at age 70 and 3.66 at age 80 when using loose collimation compared with tight collimation to the degree used in this experiment. Quite apart from the substantial reductions due to the use of tight collimation, the LAR decreases considerably with increase in age, as shown in Figure 3. 


\section{DISCUSSION}

Table 4 shows an increase in organ dose to all organs when using loose compared to tight collimation $(p=0.016)$. As might be expected, the greatest percentage increase is found in the lungs and the colon $(571 \%$ and $305 \%$ respectively), as large areas of these organs are outside the area directly irradiated when tight collimation is used. However, there is still a notable increase in organs which are outside of the primary beam with both tight and loose collimation, for example the thyroid, prostate and bladder (which increase by $150 \%$, $83.7 \%$ and $31 \%$ respectively), and this may be accounted for by the increase in scattered radiation from the much larger area of the abdomen irradiated.

A different picture emerges when tissue-weighted dose (see Table 5) is considered. Here, whilst the lungs are still subject to a large increase, the colon is much less affected and the second highest percentage increase is seen in 'other' organs (which includes active bone marrow, brain, oesophagus, thymus, breast, heart, spleen, adrenals, kidneys, pancreas, gall bladder, small intestine and testes). This is presumably due to the relatively high sensitivity of active bone marrow to ionising radiation. Other named organs show relatively little difference between organ dose increase and tissue-weighted dose increase.

Exposure to the testes (included in the 'Other' figures shown) was measured using only two TLDs and showed very low organ doses: tight collimation $=0.0004 \mathrm{mGy}$, loose collimation $=0.001 \mathrm{mGy}$. These were, of course, outside of the irradiated areas in both cases and yet the increase (more than double) could be accounted for by increased scatter.

The breasts, also represented by only two TLDs, showed a much larger increase (25 times) in organ dose from tight collimation $(0.0056 \mathrm{mGy})$ to loose collimation $(0.1404 \mathrm{mGy})$. In this case, however, the breasts were outside the tightly collimated beam but well within the loosely collimated beam. As this study was done using a male phantom, it is likely that a more representative difference would be noticed if a female phantom (or female breast attachments to the male phantom) were to be used, providing more TLD locations to represent breast dose. Further investigations are to be recommended. Doses to the ovaries were not measured for the same reason. Should they have been measured, they would have been near inclusion in the tight collimation beam and almost certainly included in loose collimation exposures. In addition, the factors in Table 12-1 produced by the National Academy of Sciences ${ }^{4}$, and used for our study, were those for male patients and the equivalents for female patients are quite different and in general higher. Again, further investigations should be done for female doses and LAR of cancer incidence.

As mentioned, all of these measurements were obtained using a setting of $75 \mathrm{kVp}$, based on the work of $\mathrm{Al}$ Qaroot et $\mathrm{al}^{8}$. It is quite likely, however, that a high $\mathrm{kVp}$ technique might be used for the purposes of measuring Cobb angles, as in scoliosis, and where a clear image of the outlines of the vertebral bodies is of more importance than bony detail. Had a higher $\mathrm{kVp}$ setting been used for this experiment, it is almost certain that the TLD readings would have been different. Again, further investigations might be in order.

Whereas the effective risk of cancer incidence is much higher when the primary beam is less collimated (wider), it is noticeable that this is much less important for older people, as is clearly shown in Figure $\mathbf{3}$. On the contrary, the most heavily affected are the youngest patients (age 20 in our study) and this is the age range where repeated examinations for scoliosis are often undertaken. It should be mentioned that accurate figures for paediatric patients were not obtained in our experiment as the phantom used was of adult size. Further investigations could be done using a smaller phantom to represent such patients. Lateral projections of the same area could also form the basis of a follow-up investigation, although in this case the difference between achievable tight and loose collimation would be a great deal less.

Although it is good practice to collimate the X-ray beam to the optimum dimensions, there is also the likelihood of over-collimating, especially in scoliosis, and in so doing failing to include all areas of interest. This would necessitate repeat exposures with the resultant doubling (or more, when less collimation would be 
used) of radiation dose. It is suggested that, in scoliosis examinations, collimation should err on the side of inclusion at least in the first instance and then follow-up examinations could be subject to tighter collimation when the extents and severity of scoliosis is known. It is also accepted that increasing the width of the collimated X-ray field will result in increased scatter to the detriment of the quality of the resultant image. However, this would be unavoidable in cases of severe scoliosis.

\section{CONCLUSION}

It stands to reason that by reducing the field size, dose will be reduced and our study has served to quantify the effects in a practical situation and, in addition, to relate dose to the LAR of cancer incidence for each decade of adult life.

The use of tight collimation, then, is to be recommended although this may be greatly limited in cases of severe scoliosis. 
Table 1 - Example of group calibration table $75 \mathrm{kVp}$

\begin{tabular}{|c|c|c|c|c|c|c|c|c|c|}
\hline \multirow{3}{*}{ mAs } & \multirow{3}{*}{$\begin{array}{l}\text { Unfors } \\
\text { dose } \\
\text { (mGy) }\end{array}$} & \multicolumn{8}{|c|}{ TLD } \\
\hline & & \multicolumn{2}{|r|}{1} & \multicolumn{2}{|r|}{2} & \multicolumn{2}{|r|}{3} & \multirow[b]{2}{*}{ Average } & \multirow{2}{*}{$\begin{array}{l}\text { Average less } \\
\text { background }\end{array}$} \\
\hline & & No. & $\begin{array}{c}\text { Charge } \\
(\mathrm{nC})\end{array}$ & No. & $\begin{array}{c}\text { Charge } \\
\text { (nC) }\end{array}$ & No. & $\begin{array}{c}\text { Charge } \\
(\mathrm{nC})\end{array}$ & & \\
\hline 10 & 0.271 & $\mathrm{~A} 1$ & 11.110 & $\mathrm{~A} 2$ & 11.060 & A3 & 10.790 & 10.987 & 10.889 \\
\hline 30 & 0.888 & B1 & 33.720 & B2 & 35.960 & B3 & 32.700 & 34.127 & 34.029 \\
\hline 50 & 1.396 & $\mathrm{C} 1$ & 55.950 & $\mathrm{C} 2$ & 58.750 & $\mathrm{C3}$ & 56.650 & 57.117 & 57.019 \\
\hline 70 & 1.988 & D1 & 77.280 & D2 & 82.690 & D3 & 78.560 & 79.510 & 79.412 \\
\hline 90 & 2.529 & E1 & 102.900 & E2 & 98.980 & E3 & 98.960 & 100.280 & 100.182 \\
\hline Background & & F1 & 0.097 & F2 & 0.100 & F3 & 0.096 & 0.098 & \\
\hline
\end{tabular}

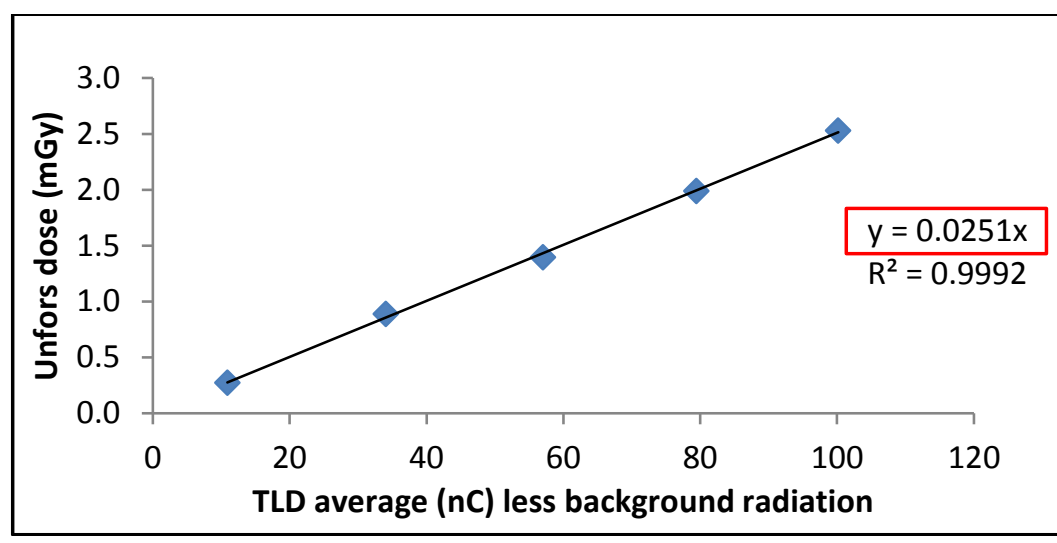

Table 2 - Extract from TLD readings table

\begin{tabular}{|c|c|c|c|c|c|c|c|c|c|c|}
\hline & periment location & Room 1 & & & Ilimation: $\mathrm{T}$ & & & osures $d$ & : 4.4.16 & \\
\hline & $/ p=75$ & As $=16$ & & $=180$ & & id & & adings dat & 4-5.4.16 & \\
\hline & $\mathrm{BM}=$ Active Bone & Marrow TL & gp BR & TLD grou & background & diation & $\mathrm{gp} C F=$ & group cal & ation fac & \\
\hline $\begin{array}{l}\text { TLD } \\
\text { no. }\end{array}$ & Organ & $\begin{array}{l}\text { Phantom } \\
\text { slice no. }\end{array}$ & Depth & $\begin{array}{l}\text { TLD gp } \\
\text { \& no on } \\
\text { tray }\end{array}$ & $\begin{array}{c}\text { TLD } \\
\text { reading } \\
(10 \exp ) \text { in } \\
\mathrm{nC}\end{array}$ & $\begin{array}{c}\text { TLD gp } \\
\text { BR }\end{array}$ & $\begin{array}{c}\text { TLD } \\
\text { reading } \\
- \text { TLD gp } \\
\text { BR }\end{array}$ & $\begin{array}{l}\text { TLD } \\
\text { reading } \\
\text { mean } \\
(/ 10)\end{array}$ & $\begin{array}{c}\text { TLD gp } \\
\text { CF }\end{array}$ & $\begin{array}{l}\text { TLD } \\
\text { reading } \\
\text { * TLD gp } \\
\text { CF }\end{array}$ \\
\hline 54 & R Lung & 14 & 5 & $2 a$ & 5.7760 & 0.0977 & 5.6783 & 0.5678 & 0.0251 & 0.0143 \\
\hline 55 & Sternum (ABM) & 14 & 20 & $2 a$ & 6.7340 & 0.0977 & 6.6363 & 0.6636 & 0.0251 & 0.0167 \\
\hline 56 & L Thymus & 14 & 12 & $2 a$ & 8.7850 & 0.0977 & 8.6873 & 0.8687 & 0.0251 & 0.0218 \\
\hline 57 & R Thymus & 14 & 12 & $2 a$ & 7.8640 & 0.0977 & 7.7663 & 0.7766 & 0.0251 & 0.0195 \\
\hline 58 & L Ribs (ABM) & 14 & 3 & $2 a$ & 1.4440 & 0.0977 & 1.3463 & 0.1346 & 0.0251 & 0.0034 \\
\hline 59 & L Ribs (ABM) & 14 & 3 & $2 a$ & 1.1620 & 0.0977 & 1.0643 & 0.1064 & 0.0251 & 0.0027 \\
\hline 60 & L Ribs (ABM) & 14 & 3 & $2 a$ & 1.7660 & 0.0977 & 1.6683 & 0.1668 & 0.0251 & 0.0042 \\
\hline 61 & R Ribs (ABM) & 14 & 3 & $2 a$ & 3.5440 & 0.0977 & 3.4463 & 0.3446 & 0.0251 & 0.0087 \\
\hline 62 & R Ribs (ABM) & 14 & 3 & $2 a$ & 1.3060 & 0.0977 & 1.2083 & 0.1208 & 0.0251 & 0.0030 \\
\hline 63 & R Ribs (ABM) & 14 & 3 & $2 a$ & 1.2390 & 0.0977 & 1.1413 & 0.1141 & 0.0251 & 0.0029 \\
\hline 64 & L Scapula (ABM) & 14 & 5 & $2 a$ & 0.6547 & 0.0977 & 0.5570 & 0.0557 & 0.0251 & 0.0014 \\
\hline
\end{tabular}


Figure 1 - Photograph and radiograph showing extents of tight collimation

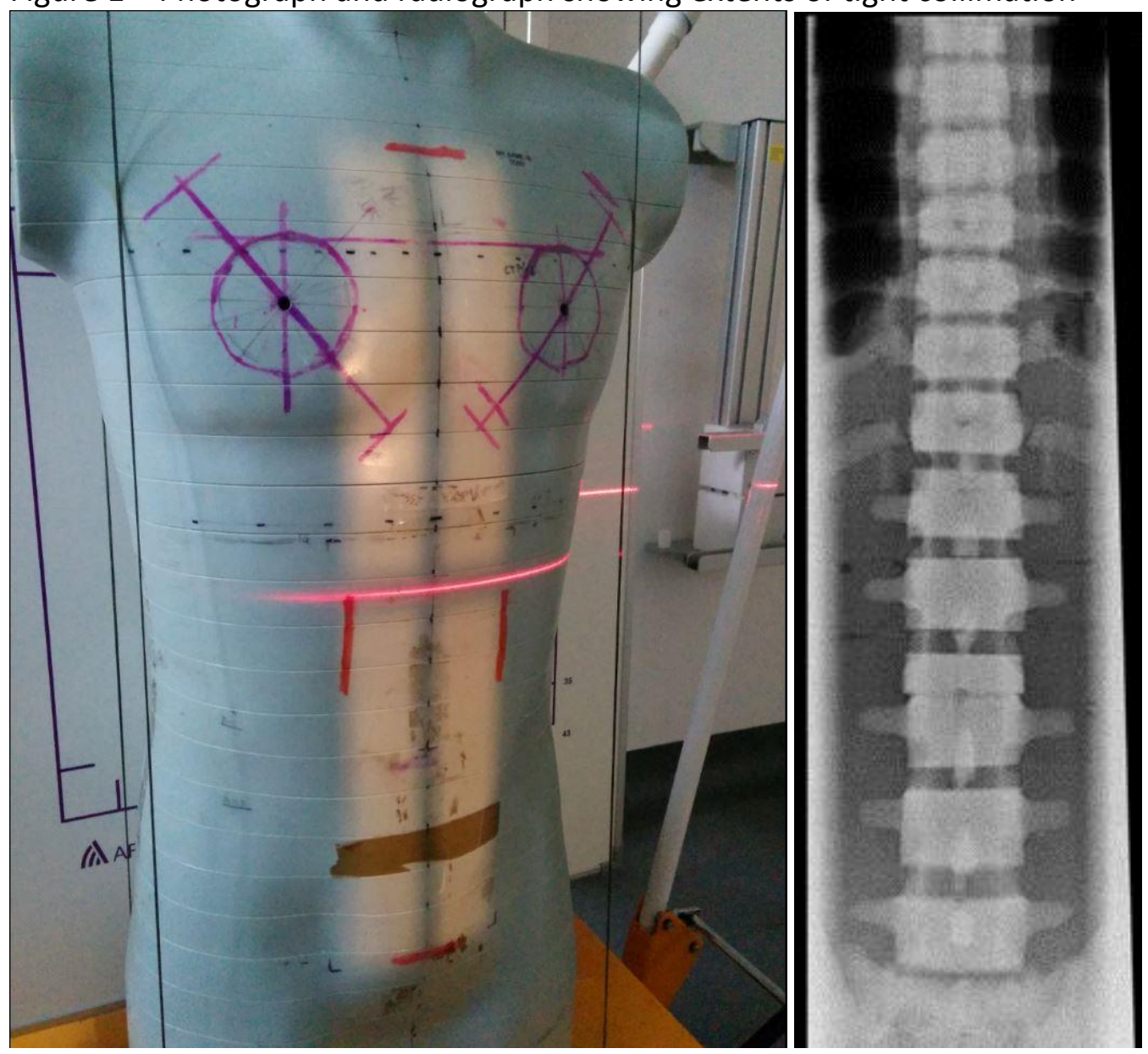

Figure 2 - Photograph and radiograph showing extents of loose collimation

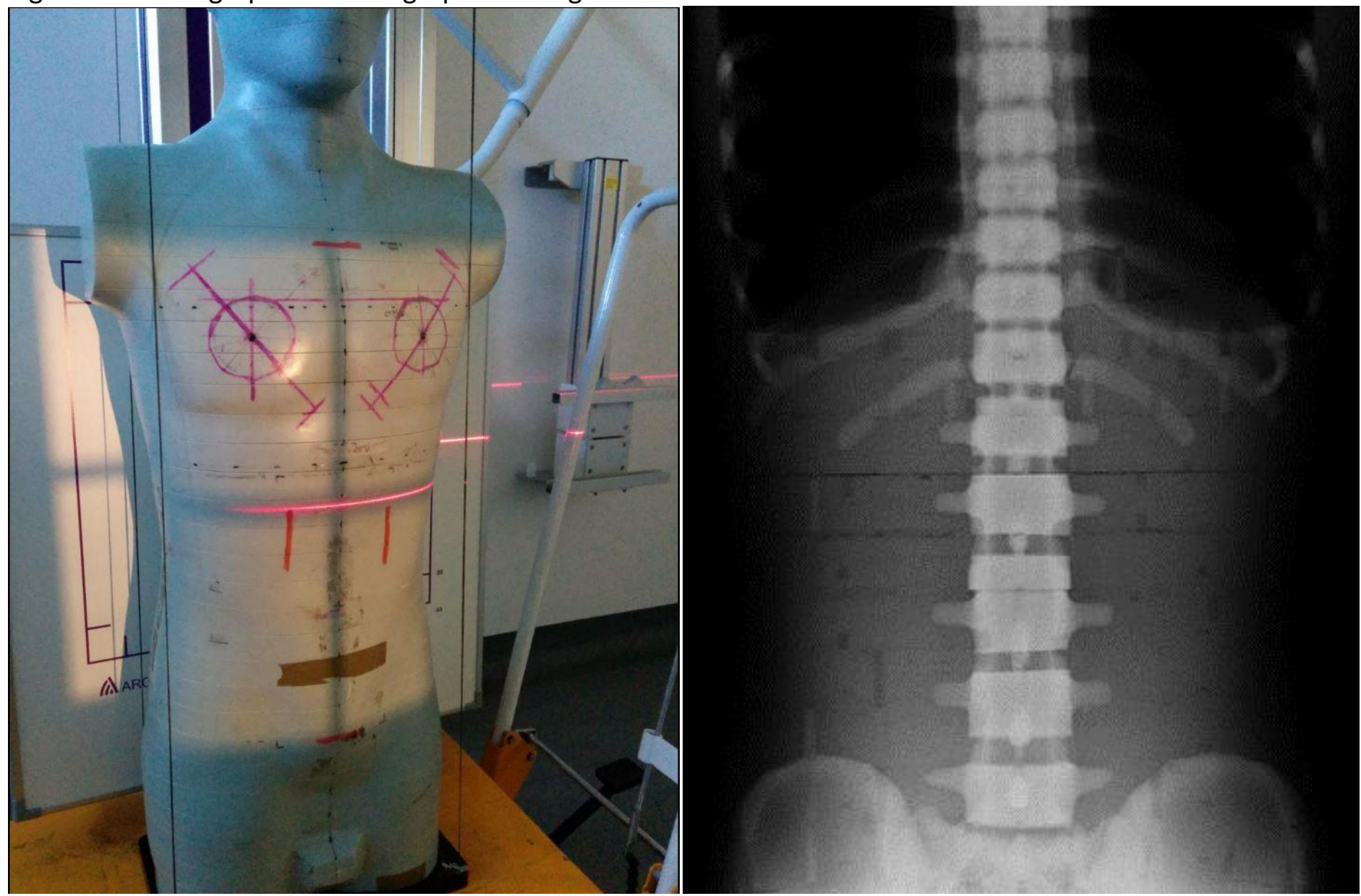


Table 3 - Lifetime attributable risk calculations

\begin{tabular}{|c|c|c|c|c|c|c|c|c|c|c|c|}
\hline & $\begin{array}{c}\text { Average } \\
\text { dose (mGy) }\end{array}$ & $\begin{array}{c}\text { Average } \\
\text { dose(mGy) }\end{array}$ & \multicolumn{9}{|c|}{ Lifetime Attributable Risk of cancer incidence - number of cases per 1,000,000 persons exposed } \\
\hline Colon & 0.016622 & 0.067286 & 17.30 & 0.287569 & 1.164053 & 12.50 & 0.207781 & 0.841079 & 12.20 & 0.202794 & 0.820893 \\
\hline Liver & 0.029591 & 0.064113 & 3.00 & 0.088772 & 0.192339 & 2.20 & 0.065100 & 0.141049 & 2.10 & 0.062140 & 0.134637 \\
\hline Lungs & 0.007196 & 0.048305 & 14.90 & 0.107226 & 0.719741 & 10.50 & 0.075562 & 0.507200 & 10.40 & 0.074842 & 0.502370 \\
\hline Thyroid & 0.001555 & 0.003891 & 2.10 & 0.003265 & 0.008171 & 0.90 & 0.001399 & 0.003502 & 0.30 & 0.000466 & 0.001167 \\
\hline Other & 0.007809 & 0.018833 & 31.20 & 0.243641 & 0.587597 & 19.80 & 0.154618 & 0.372898 & 17.20 & 0.134315 & 0.323932 \\
\hline Effective risk & & & & 0.969270 & 3.122999 & & 0.675191 & 2.186264 & & 0.642167 & 2.096064 \\
\hline
\end{tabular}

\begin{tabular}{|c|c|c|c|c|c|c|c|c|c|c|c|c|}
\hline Stomach & 2.50 & 0.078060 & 0.186784 & 2.00 & 0.062448 & 0.149427 & 1.40 & 0.043714 & 0.104599 & 0.07 & 0.002186 & 0.005230 \\
\hline Liver & 1.90 & 0.056222 & 0.121815 & 1.40 & 0.041427 & 0.089758 & 0.80 & 0.023673 & 0.051290 & 0.30 & 0.008877 & 0.019234 \\
\hline Lungs & 10.10 & 0.072683 & 0.487878 & 8.90 & 0.064048 & 0.429912 & 6.50 & 0.046776 & 0.313981 & 3.40 & 0.024468 & 0.164236 \\
\hline Prostate & 3.30 & 0.003950 & 0.007257 & 2.60 & 0.003112 & 0.005718 & 1.40 & 0.001676 & 0.003079 & 0.50 & 0.000599 & 0.001100 \\
\hline Other & 14.00 & 0.109326 & 0.263665 & 9.80 & 0.076528 & 0.184566 & 5.70 & 0.044511 & 0.107349 & 2.30 & 0.017961 & 0.043316 \\
\hline Effective risk & & 0.584341 & 1.927830 & & 0.469956 & 1.578576 & & 0.315479 & 1.079359 & & 0.126990 & 0.465149 \\
\hline
\end{tabular}

Figure 3-Graphical representation of lifetime attributable risk calculations

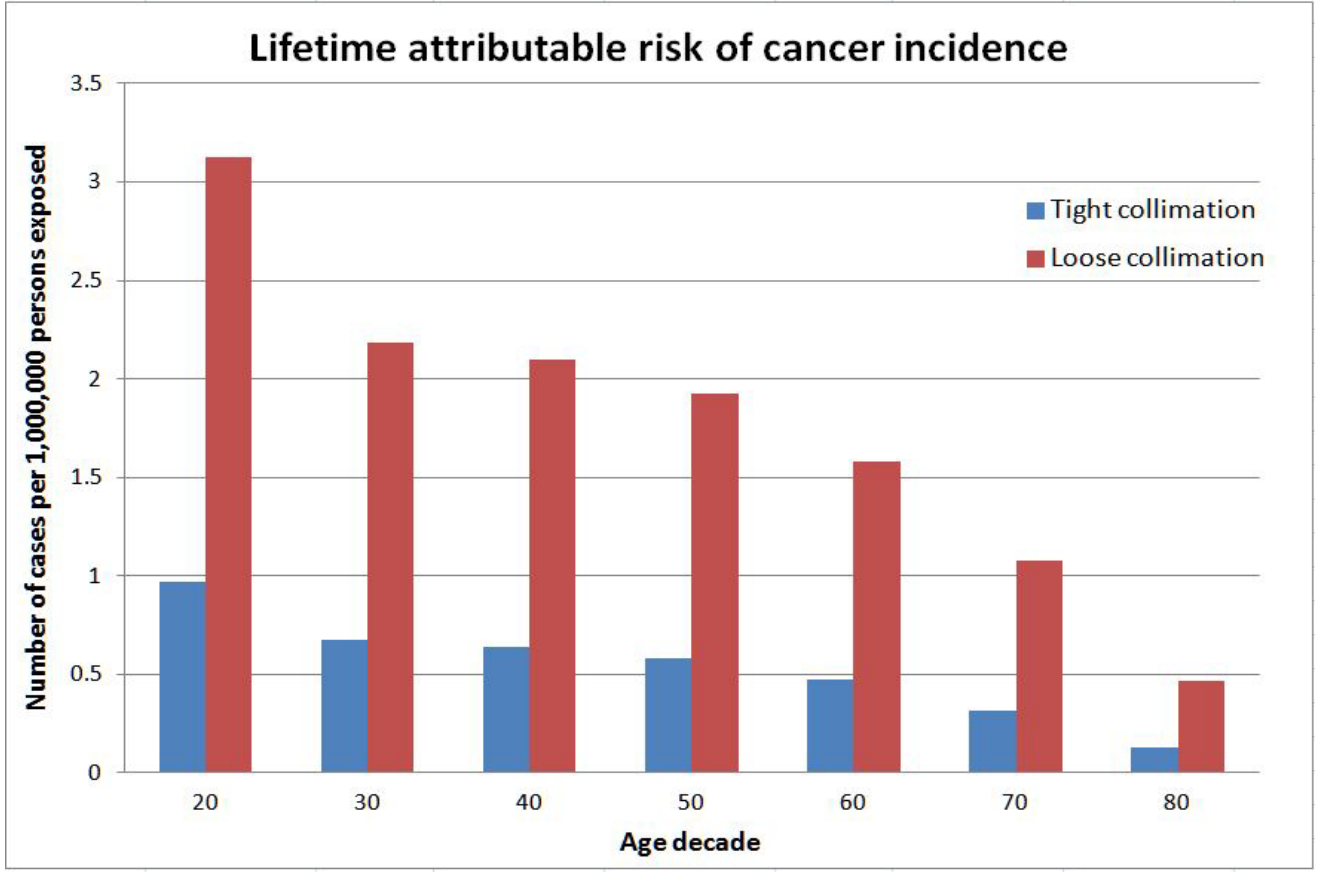


Table 4 - Increase in organ dose from tight to loose collimation

\begin{tabular}{|l|c|c|c|c|}
\hline & \multicolumn{2}{|c|}{ Organ dose (mGy) } & & \\
\hline Organ & Tight collimation & Loose collimation & Increase & $\%$ increase \\
\hline Stomach & 0.031224 & 0.074714 & 0.043490 & $139.28 \%$ \\
\hline Colon & 0.016622 & 0.067286 & 0.050664 & $304.79 \%$ \\
\hline Liver & 0.029591 & 0.064113 & 0.034522 & $116.67 \%$ \\
\hline Lungs & 0.007196 & 0.048305 & 0.041108 & $571.24 \%$ \\
\hline Prostate & 0.001197 & 0.002199 & 0.001002 & $83.72 \%$ \\
\hline Bladder & 0.010014 & 0.013119 & 0.003105 & $31.00 \%$ \\
\hline Thyroid & 0.001555 & 0.003891 & 0.002336 & $150.24 \%$ \\
\hline Other & 0.007809 & 0.018833 & 0.011024 & $141.17 \%$ \\
\hline
\end{tabular}

Table 5 - Increase in tissue-weighted dose from tight to loose collimation

\begin{tabular}{|l|c|c|c|c|}
\hline & \multicolumn{2}{|c|}{ Tissue-weighted dose (mSv) } & & \\
\hline Organ & Tight collimation & Loose collimation & Increase & $\%$ increase \\
\hline Stomach & 0.003747 & 0.008966 & 0.005219 & $139.28 \%$ \\
\hline Colon & 0.001995 & 0.004515 & 0.002520 & $126.35 \%$ \\
\hline Liver & 0.001184 & 0.002565 & 0.001381 & $116.67 \%$ \\
\hline Lungs & 0.000864 & 0.005797 & 0.004933 & $571.24 \%$ \\
\hline Prostate & 0.000013 & 0.000024 & 0.000011 & $83.72 \%$ \\
\hline Bladder & 0.000401 & 0.000525 & 0.000124 & $31.00 \%$ \\
\hline Thyroid & 0.000062 & 0.000156 & 0.000093 & $150.24 \%$ \\
\hline Other & 0.000282 & 0.001737 & 0.001455 & $516.85 \%$ \\
\hline Effective dose & 0.008546 & 0.024283 & 0.015737 & \\
\hline
\end{tabular}

References:

1. Don, S., MacDougall, R., Strauss, K., Moore, Q.T., Goske, M.J., Cohen, M., Herrmann, T., John, S.D., Noble, L., Morrison, G., Lehman, L., Whiting, B.R. Image gently campaign back to basics initiative: Ten steps to help manage radiation dose in pediatric digital radiography (2013) American Journal of Roentgenology, 200 (5), pp. W431-W436.

2. Powys, R., Robinson, J., Kench, P. L., Ryan, J., Brennan, P. C. Strict X-ray beam collimation for facial bones examination can increase lens exposure (2012) British Journal of Radiology

3. Lee, B., Lee, S., Yang, I., Yoon, M. Evaluation of the stepwise collimation method for the reduction of the patient dose in full spine radiography (2014) Journal of the Korean Physical Society

4. National Academy of Sciences. Health Risks from Exposure to Low Levels of lonising Radiation: BEIR VII Phase 2. The National Academies Press(2006) Washington DC. ISBN: 978-0-309-09156-5

5. Zetterberg, L.G., Espeland, A. Lumbar spine radiography - Poor collimation practices after implementation of digital technology (2011) British Journal of Radiology, 84 (1002), pp. 566-569.

6. Brennan, P.C., O'Leary, D. Source to image receptor distance [1] (2006) British Journal of Radiology, 79 (939), p. 266.

7. Mekis, M., McEntee, M.F., Stegnar, P. PA positioning significantly reduces testicular dose during sacroiliac joint radiography (2010) Radiography

8. Al Qaroot, B., Hogg, P., Twiste, M., Howard, D. A systematic procedure to optimise dose and image quality for the measurement of inter-vertebral angles from lateral spinal projections using Cobb and superimposition methods (2014) Journal of X-Ray Science and Technology, 22, p. 613

9. ICRP. The 2007 Recommendations of the International Commission on Radiological Protection. ICRP publication 103 (2007) Ann ICRP, 37(2-4):1-332. 